\title{
Thyrotropin receptor signaling deficiency impairs spatial learning and memory in mice
}

\author{
Sisi Luan 1,2,3,4, Wenkai Bi1,2,3,4, Shulong Shi1,2,3, Li Peng1,2,3,4, Zhanbin Li1,2,3,4, Jie Jiang1,2,3,4, Ling Gao 1,2,3, Yifeng Du5, \\ Xu Hou1,6,7, Zhao He1,2,3,4,6 and Jiajun Zhao 1,2,3,6 \\ 1Department of Endocrinology, Shandong Provincial Hospital, Cheeloo College of Medicine, Shandong University, Jinan, Shandong, China \\ 2Shandong Provincial Key Laboratory of Endocrinology and Lipid Metabolism, Jinan, Shandong, China \\ IInstitute of Endocrinology and Metabolism, Shandong Academy of Clinical Medicine, Jinan, Shandong, China \\ ${ }^{4}$ Cheeloo College of Medicine, Shandong University, Jinan, Shandong, China \\ ${ }^{5}$ Department of Neurology, Shandong Provincial Hospital affiliated to Shandong First Medical University, Jinan, Shandong, China \\ ${ }^{6}$ Department of Endocrinology, Shandong Provincial Hospital affiliated to Shandong First Medical University \& Shandong Academy of Medical Sciences, \\ Jinan, Shandong, China \\ 7Stem Cell Research Center, Shandong Provincial Hospital affiliated to First Medical University \& Shandong Academy of Medical Sciences, Jinan, \\ Shandong, China
}

Correspondence should be addressed to X Hou or Z He or J Zhao: 15153285655@163.com or zhaohe7711@qq.com or jjzhao@sdu.edu.cn

\begin{abstract}
Subclinical hyperthyroidism, a condition characterized by decreased thyroid-stimulating hormone (TSH) and normal concentration of thyroid hormone, is associated with an elevated risk for cognitive impairment. TSH is the major endogenous ligand of the TSH receptor (TSHR) and its role is dependent on signal transduction of TSHR. It has not, however, been established whether TSHR signaling is involved in the regulation of cognition. Here, we utilized Tshr knockout mice and found that Tshr deletion led to significantly compromised performance in learning and memory tests. Reduced dendritic spine density and excitatory synaptic density as well as altered synaptic structure in CA1 subfield of the hippocampus were also noted. Furthermore, the synapse-related gene expression was altered in the hippocampus of Tshr-l-mice. These findings suggest that TSHR signaling deficiency impairs spatial learning and memory, which discloses a novel role of TSHR signaling in brain function.
\end{abstract}

\section{Key Words}

- TSHR

- cognitive function

- hippocampus

- learning and memory

\section{Introduction}

Thyroid hormones are produced and released by the thyroid gland, which regulate the metabolism of the body. The endocrine function of the thyroid gland is mediated by TSH, a glycoprotein hormone produced by the anterior pituitary gland (Marians etal. 2002). Overt thyroid disorders, characterized by abnormal levels of both TSH and thyroid hormones, are associated with cognitive dysfunction. As thyroid hormones play a central role in governing neurogenesis and gliogenesis from development to ageing (Lopez-Juarez et al. 2012, Remaud et al. 2014, 2017, Gothie et al. 2020), the association has been traditionally attributed to abnormal thyroid hormone levels. In recent years, accumulating evidence has demonstrated that cognitive impairment is associated with subclinical hyperthyroidism, a condition characterized by low or undetectable serum TSH level with a normal serum thyroid hormone level (Biondi \& Cooper 2008, Gan \& Pearce 2012, Rieben et al. 2016). The decline in cognitive function cannot be explained by abnormal thyroid hormones, rather it is likely that TSH plays a role in cognitive functions.

TSH is the major endogenous ligand of TSHR, a member of the $G$ protein-coupled receptor (GPCR) 
family. Binding of TSH to TSHR results in intracellular signaling via cyclic AMP (cAMP) and can induce both the phospholipase $\mathrm{C}$ and the protein kinase A signal transduction systems (Davies et al. 2002) thereby exerting a variety of physiological functions. Although TSHR is of great importance for various functional aspects of thyroid gland, it has been shown to be expressed and to play roles in other organs, such as the liver, skin, and bone (Abe et al. 2003, Zhang et al. 2009, Cianfarani et al. 2010). In the CNS, TSHR expression has been detected in large neuronal cell bodies within all six limbic regions in the human brain (Naicker \& Naidoo 2018). Meanwhile, TSH has been found in brain and cerebrospinal fluid as well (Hojvat et al. 1982, Zaidman et al. 1985).

Based on the previously mentioned studies, we speculated that TSHR signaling may play a role in cognitive function. In the current study, we utilized Tshr knockout mouse model to elucidate the previously mentioned hypothesis via behavioral tests, analysis of the synaptic structure and gene expression profiling. Our results clearly show that TSHR signaling deficiency induces cognitive impairment, which uncovers a novel role of TSHR signaling in brain function.

\section{Materials and methods}

\section{Human subjects}

The present population-based study was part of the community-based REACTION study that aimed to investigate the epidemiology of metabolic diseases (Ning \& Reaction Study Group 2012). A total of 969 participants ranged in ages from 21 to 82 years from our long-term follow-up research center of Ningyang in China were involved in the study. The study was approved by the ethics committee of Shandong Provincial Hospital, and written informed consent was obtained from each participant before collecting data. All the participants underwent a standard examination in the morning including the following: a detailed medical history inquiry; mini-mental state examination (MMSE); measurement of height, body weight, waist circumference and blood pressure; collection of fasted serum sample. Age, sex, smoking status and family history of Alzheimer's disease and other essential information were obtained via questionnaire. Subjects were fasted for at least $10 \mathrm{~h}$ before serum sample collection between 07:00 and 08:00 $\mathrm{h}$. Thyroid function was assessed by serum levels of TSH, FT3 and FT4, using immunoassay analyzer (Cobas E602; Roche). The following participants were excluded: (1) those who were using medications that can alter thyroid function, including levothyroxine, methimazole, amiodarone, carbidopa, phenytoin, lithium, rifampicin; (2) those who were using drugs that indicate neurologic or psychiatric disease or could directly interfere with performance on cognitive tests, such as neuroleptics, antiparkinsonian agents, and anticonvulsants; (3) those with complications or conditions that can affect cognitive function, including cerebral infarction, brain trauma and general anesthesia; and (4) those who were missing vital data (details shown in Fig. 1A). Eventually, 382 participants were included and analyzed. The participants were classified into four groups according their TSH level.

\section{Mini-mental state examination}

The Chinese version of MMSE translated and modified by Katzman and colleagues was employed to assess cognitive function, using a scoring scale totaling 30 points (Katzman et al. 1988). The MMSE contains 11 questions and is divided into 2 sections and takes approximately 5 to $7 \mathrm{~min}$ to administer. The first section requires the participant to respond verbally to questions focusing on memory, attention, and orientation. The second section assesses the patient's ability to follow verbal and written commands and involves writing a sentence and drawing a polygon figure. The cut-off points of MMSE for normal cognitive functioning were $19 / 20$ for illiterate, $22 / 23$ for individuals with 1-6 years of education, and $26 / 27$ for individuals with 7 or more years of education (Crum et al. 1993, Zhang et al. 1999) (detailed in Fig. 1B).

\section{Animals, genotypes, and diet}

Tshr- mice were obtained from the Jackson Laboratories. Mice were maintained in $12 \mathrm{~h}$ light: $12 \mathrm{~h}$ darkness cycles with free access to food and water. To maintain thyroid hormones within physiological levels, Tshr- pups were nursed by dams fed a diet supplemented with 100 ppm thyroid hormone powder (Sigma) and then, after weaning, fed the supplemented diet (Noguchi et al. 1985, Roepke et al. 2009). All animals used for the experiments were backcrossed at least six generations, confirmed to have $99 \%$ C57BL/6 genetic background by genome wide SNP analysis and were maintained in standard animal facilities. Serum levels of total T4 and T3 were measured using RIA kits (Jiuding Tianjin Biological Products Co., Tianjin, China). Male mice were used for all experiments at 3 months old unless stated otherwise. The animal experimental protocol was approved by the Animal Ethics Committee of Shandong Provincial Hospital. 
A

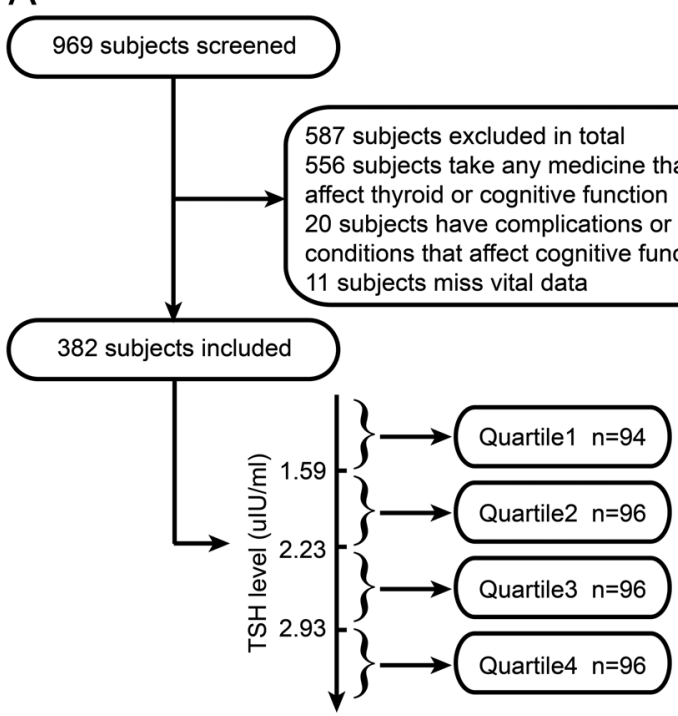

B

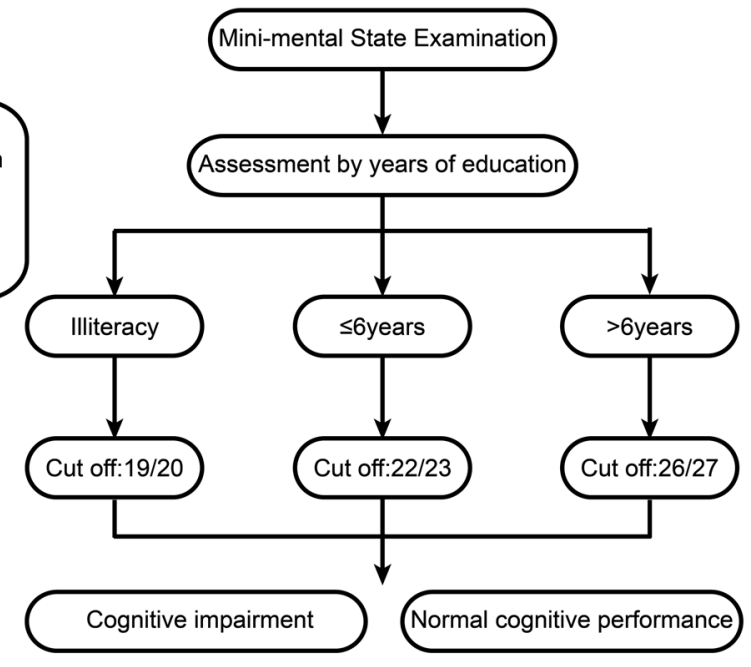

Figure 1

Study participants' flow-chart and statistical analysis. (A) After the exclusion, the included subjects were divided into four groups according to serum TSH levels. (B) The cut-off points for cognitive impairment of mini-mental state examination. Cut-off values are referred from Crum et al. 1993 , Zhang et al. 1999. To study the relationship between TSH and cognitive impairment, binary logistic regression analysis was performed. TSH was defined as a dummy variable and TSH quartiles were compared to the fourth quartile (Quartile 4).

\section{Water maze place navigation}

Morris water maze was performed to assess the spatial learning and memory of mice (Vorhees \& Williams 2006). Briefly, the apparatus consists of a large circular pool, 1.5 $\mathrm{m}$ in diameter and a height of $35 \mathrm{~cm}$ containing milky water $\left(22-24^{\circ} \mathrm{C}\right)$. Habituation training was on day 0 . The learning trials were conducted over 5 consecutive days (day 1-day 5), with four trials per day. On day 6 (probe day), $24 \mathrm{~h}$ after the previous training, the escape platform was removed before conducting the spatial probe trials. The cutoff time for animals to swim was set to $60 \mathrm{~s}$ before the end of session. Passive floating episodes, defined as immobility or decelerations with minimum speed $<0.06 \mathrm{~m} / \mathrm{s}$, were removed from the data. Percentage of time in target quadrant and time of passing the removed escape platform were measured to evaluate the capability of spatial memory.

\section{Y maze}

Y-maze test was performed to detect the short-term spatial working memory of mice (Lalonde 2002). Testing was carried out using a Y-shaped maze with three light-colored, opaque arms orientated at $120^{\circ}$ angles from each other. Each mouse was placed at the center of the apparatus and allowed to move freely through the maze during an 8-min session. Alternation was defined as successive entry into the three different arms, counting overlapping triplet

\begin{tabular}{|lr} 
https://joe.bioscientifica.com & (c) 2020 Society for Endocrinology \\
https://doi.org/10.1530/JOE-20-0026 & Published by Bioscientifica Ltd. \\
Printed in Great Britain
\end{tabular}

sets. Alternation behavior (\%) was calculated as the ratio of actual alternations to possible alternations (defined as the number of arm entries minus two).

Trials were video tracked and analyzed using a SMART v3.0 system (SMART VIDEO TRACKING Software, Harvard Apparatus, Holliston, MA, USA).

\section{Tissue processing and Nissl staining}

Briefly, mice were killed with 3\% pentobarbital and transcardially perfused with chilled $0.9 \%$ saline. Brains were dissected and postfixed in $4 \%$ paraformaldehyde for $24 \mathrm{~h}$ at $4^{\circ} \mathrm{C}$ and then preserved in $20 \%$ and $30 \%$ sucrose for $24 \mathrm{~h}$ in PBS each. Brains were sectioned coronally at a thickness of $30 \mu \mathrm{m}$ on a freezing-sliding microtome (CM1950, Leica), and sections were stored in cryoprotective medium at $-20^{\circ} \mathrm{C}$. The sections were transferred on the positively charged anti-off slide and left to air dry for $2 \mathrm{~h}$ at room temperature before Nissl staining. After staining in $0.1 \%$ cresyl violet solution (Goodbio Technology, Wuhan, China) for $10 \mathrm{~min}$, the sections were rinsed quickly in distilled water and differentiated in 95\% ethyl alcohol for $7 \mathrm{~s}$ and checked microscopically for best result. The slices were dehydrated in 70\% ethyl alcohol and $100 \%$ ethyl alcohol twice for $5 \mathrm{~min}$ each, cleared in xylene. Photographs of brain sections were taken by a slide-scanning system (TissueFAXS PLUS, Vienna, Austria). 


\section{Immunohistochemistry}

Cryosections of brain tissue were prepared as described. Free-floating sections were blocked with appropriate serum for $1 \mathrm{~h}$ before incubation at $4^{\circ} \mathrm{C}$ overnight with primary antibodies: NeuN (ab177487, abcam); PhosphoCREB (Ser133) (4695, Cell Signalling Technology); FOS (2250, Cell Signalling Technology); and EGR1 (4151, Cell Signalling Technology). For light microscopy, staining was visualized by incubating sections with respective biotinylated secondary antibodies, followed by Polink-1 HRP detection system (ZSGB Bio, Beijing, China). Images of brain sections were acquired by TissueFAXS PLUS. Quantitative analysis was performed by HistoQuest software (TissueGnostics, Vienna, Austria) to count the number of NeuN-positive, pCREB-positive, FOS-positive, and EGR1-positive cells in subfields of hippocampus in 3-5 coronal slices (spaced $360 \mathrm{~mm}$ from each other) per mouse. All counts were performed in a blinded fashion.

\section{Golgi staining}

After removal, the brains were immersed in modified Golgi-Cox staining Solution A and B of FD Rapid GolgiStain $^{\mathrm{TM}}$ Kit (FD Neurotechnologies, Columbia, MD, USA) for 2 weeks at room temperature in darkness. Brains were then transferred to Solution $\mathrm{C}$ at room temperature for at least $72 \mathrm{~h}$. Sections $(120 \mu \mathrm{m})$ were mounted onto gelatin-coated microscope slides (FD Neurotechnologies). After drying naturally at room temperature, slides were placed in a mixture consisting of Solution D, Solution E, and double distilled water for $10 \mathrm{~min}$. After being rinsed, slides were dehydrated in 50\%, 75\%, and 95\% ethanol and absolute ethanol and finally cleared in xylene and covered by coverslips in permount. Images of neurons were acquired at $1000 \times$ magnification by TissueFAXS PLUS, and subsequent dendritic spine analysis were performed on selected segments of hippocampal CA1 pyramidal neurons by ImageJ software (NIH).

\section{Transmission electron microscopy (TEM)}

TEM was applied to observe the ultrastructural changes of CA1 subfield of murine hippocampus. Mice were deeply anesthetized and perfused with heparinized saline followed by a fixative containing $4 \%$ paraformaldehyde and $0.1 \%$ glutaraldehyde in $0.1 \mathrm{M}$ phosphate buffer ( $\mathrm{pH}$ 7.35). The brains were removed and immersed in a fixative solution $(2.5 \%$ glutaraldehyde in $0.1 \mathrm{mmol} / \mathrm{L}$ sodium cacodylate, $\mathrm{pH}$ 7.4) overnight. The hemispheric tissue blocks containing hippocampus were cut into $400-\mu \mathrm{m}$-thick coronal slices. After post-fixation in 1\% osmium tetroxide ( $\mathrm{pH} 7.4)$, the hippocampus cut out from the coronal slices were embedded in epoxy resin Epon 812 and cut into ultra-thin sections of $50 \mathrm{~nm}$ using an ultramicrotome (Leica EM UC6). Sections were counterstained with uranyl acetate and lead citrate, and the ultrastructure of hippocampal CA1 subfield was examined using a JEM-1200 EX electron microscope (FEI).

For morphometry, images from CA1 subfield of each animal were examined at 30,000× magnification. Asymmetric (type 1) synapses were defined as contacts with a visible synaptic cleft, a distinct postsynaptic density and at least four synaptic vesicles. In perforated type 1 synapses, the postsynaptic density was classified as discontinuous. Total asymmetric synapses and perforated synapses were quantified as area densities, and the ratio of perforated to non-perforated synapses was calculated. For additional parameter measurements, images were analyzed at magnification of 60,000x. Electron microscopic analysis were performed by ImageJ Pro Plus software (Media Cybernetics, Rockville, MD, USA).

\section{RNA sequencing (RNA-seq)}

A total amount of $3 \mu \mathrm{g}$ RNA per sample was used as the input material for transcriptomic analysis. Sequencing libraries were generated using NEBNext UltraTM RNA Library Prep Kit for Illumina ${ }^{\circledR}$ (NEB, Ipswich, MA, USA) and index codes were added to attribute sequences to each sample. The clustering of the index-coded samples was performed on a cBot Cluster Generation System using TruSeq PE Cluster Kit v3-cBot-HS (Illumia) according to the manufacturer's instructions. After cluster generation, the library preparations were sequenced on an Illumina Novaseq platform and 150-bp paired-end reads were generated. The data has been uploaded to Gene Expression Omnibus database (GSE145958).

Differential expression analysis of two groups (five biological replicates per genotype) was performed using the DESeq2 R package (1.16.1). DESeq2 provide statistical routines for determining differential expression in digital gene expression data using a model based on the negative binomial distribution. The resulting $P$-values were adjusted using the Benjamini and Hochberg's approach for controlling the false discovery rate. Genes with an adjusted $P$-value of $<0.05$ found by DESeq 2 were assigned as differentially expressed. ClusterProfiler $\mathrm{R}$ package was used to test the statistical enrichment of differentially expressed genes (DEGs) in Kyoto encyclopedia of genes 
Table 1 Sequences of the primers used for real-time PCR in this study.

\begin{tabular}{lr}
\hline Gene & Gene ID \\
\hline Actb & 11461 \\
Arc & 11838 \\
Bdnf & 12064 \\
Cebpb & 12608 \\
Fos & 14281 \\
Egr1 & 13653 \\
Egr2 & 13654 \\
Grin2a & 14811 \\
Homer1 & 26556 \\
Itpr1 & 16438 \\
Junb & 16477 \\
Kcnab1 & 16497 \\
Klk8 & 259277 \\
Npas4 & 225872 \\
Ppp3ca & 19055 \\
Shank3 & 58234 \\
Tanc1 & 66860 \\
Tshr & 22095 \\
\hline
\end{tabular}

\begin{tabular}{l}
\hline \multicolumn{1}{c}{ Forward } \\
\hline Sequence, \\
\hline GATCTGGCACCACACCTTCT \\
AAGTGCCGAGCTGAGATGC \\
TCATACTTCGGTTGCATGAAGG \\
GACGAGTACAAGATGCGGCG \\
CGGGTTTCAACGCCGACTA \\
TCGGCTCCTTCCTCACTCA \\
GCCAAGGCCGTAGACAAAATC \\
ACGTGACAGAACGCGAACTT \\
CCCTCTCTCATGCTAGTTCAGC \\
CGTTTTGAGTTTGAAGGCGTTT \\
TCACGACGACTCTTACGCAG \\
AGGACCGACTTCTGAGCAAG \\
GATCCTGGAAGGTCGAGAGTG \\
CAGATCAACGCCGAGATTCG \\
GTGAAAGCCGTTCCATTTCCA \\
ATGGGCCTGTGTGGTAGTCTT \\
CTGCTGGGAGAGGAAAGGTG \\
TCAATGGAACAAAGCTGGATG
\end{tabular}

\begin{tabular}{l} 
Reverse \\
\hline GGGGTGTTGAAGGTCTCAAA \\
CGACCTGTGCAACCCTTTC \\
AGACCTCTCGAACCTGCCC \\
GAACAAGTTCCGCAGGGTG \\
TTGGCACTAGAGACGGACAGA \\
CTCATAGGGTTGTTCGCTCGG \\
CCACTCCGTTCATCTGGTCA \\
TCAGTGCGGTTCATCAATAACG \\
GCACAGCGTTTGCTTGACT \\
CATCTTGCGCCAATTCCCG \\
CCTTGAGACCCCGATAGGGA \\
GATAGCGACAGTGCGGAATTT \\
CTGCTCCGGCTGATCTCTG \\
CACCCTTGCGAGTGTAGATGC \\
GAATCGAAGCACCCTCTGTTATT \\
CCACCTTATCTGTGCTGTGTAG \\
CAATCGGACAACCTGCCAAT \\
CCGAGTGAGGTGGAGGAAAC
\end{tabular}

and genomes (KEGG) pathways and gene ontology (GO) enrichment analysis. The protein-protein interaction (PPI) network of DEGs was constructed using a STRING online software. The hub genes were identified by the CytoHubba plugin of Cytoscape software (Shannon et al. 2003).

\section{Real-time polymerase chain reaction (real-time PCR)}

The hippocampal tissue was washed briefly in PBS, snap frozen with liquid nitrogen, grinded quickly, and dissolved with $1 \mathrm{~mL}$ of RNAiso Plus (Takara Bio). RNA was quantified with a Nanodrop 2000 (Thermo Fisher), and $1 \mu \mathrm{g}$ of total RNA from each sample was used as the template in a $20-\mu \mathrm{L}$ retro-transcriptional system using Primescript RT Reagent kit (Perfect Real Time, Takara Bio) according to the manufacturer's instructions. The real-time PCR for specific genes was performed using Bestar SYBR Green qPCR Master Mix (DBI Bioscience, Ludwigshafen, Germany) on a Light Cycler480 (Roche Diagnostics). Sequences of primers used for real-time PCR in this study are displayed in Table 1 . The housekeeping gene $A c t b$ was used as internal standard. Cq values for each reaction were determined using second derivative maximum method, and the amplification efficiency was presumed to be 2 for fold change calculation.

\section{Immunoblotting}

Hippocampal tissue proteins extracted from mice were separated by SDS-PAGE and transferred to

(C) 2020 Society for Endocrinology Published by Bioscientifica Ltd. Printed in Great Britain polyvinyldifluoride membranes (Millipore). After being blocked with 5\% non-fat milk in TBST (pH 7.4, 20 mM Tris$\mathrm{HCl}, 15 \mathrm{~m} \mathrm{M} \mathrm{NaCl}, 0.1 \%(\mathrm{v} / \mathrm{v})$ Tween 20), the membranes were incubated overnight at $4^{\circ} \mathrm{C}$ with primary antibodies. The primary antibodies were as follows: BDNF (ab108319, Abcam) and GAPDH (60004-1-Ig, Proteintech). After washing with TBST, the membranes were incubated for $1 \mathrm{~h}$ at room temperature with the appropriate HRPconjugated secondary antibody. The bands were visualized by FluorChemQ system via a chemiluminescence kit (Pierce).

\section{Statistical analysis}

Quantitative variables for population data are expressed as mean \pm s.D. or median (inter-quartile range). Continuous variables were compared using one-way ANOVA test or Kruskall-Wallis test and categorical variables by using Chi-squared test. Intergroup comparisons were performed using post-hoc Bonferroni test, and $P<0.05$ was considered significant. Binary logistic regression analysis was performed to study the relationship between TSH and cognitive impairment. TSH was defined as a dummy variable and TSH quartiles were compared to the fourth quartile. Experimental data are presented as mean \pm s.E.M. unless stated otherwise. Twogroup comparisons were made using unpaired Student's $t$-test, and two-sided $P \leq 0.05$ was considered significant. Population data was analyzed with SPSS v.22.0 (IBM), while experimental data was analyzed with Prism 6.0 (Graphpad). 
Table 2 Characteristics of participants according to TSH quartile $(n=382)$

\begin{tabular}{|c|c|c|c|c|c|c|}
\hline & \multirow[b]{2}{*}{ All } & \multicolumn{4}{|c|}{ TSH } & \multirow[b]{2}{*}{ P-value } \\
\hline & & $\begin{array}{c}\text { Quartile 1 } \\
(<1.59 \mu \mathrm{IU} / \mathrm{mL})\end{array}$ & $\begin{array}{c}\text { Quartile } 2 \\
(1.59,2.23 \mu \mathrm{lU} / \mathrm{mL}) \\
\end{array}$ & $\begin{array}{c}\text { Quartile } 3 \\
(2.23,2.93 \mu \mathrm{IU} / \mathrm{mL}) \\
\end{array}$ & $\begin{array}{c}\text { Quartile } 4 \\
(\geq 2.93 \mu \mathrm{IU} / \mathrm{mL})\end{array}$ & \\
\hline Age (year) & $58.60 \pm 9.54$ & $59.27 \pm 8.83$ & $57.93 \pm 9.70$ & $57.42 \pm 10.27$ & $59.82 \pm 9.23$ & NS \\
\hline Male $(\%)$ & $163(43.4)$ & $40(42.1)$ & $51(54.8)$ & $42(43.8)$ & $30(32.6)^{b}$ & 0.025 \\
\hline $\mathrm{BMI}\left(\mathrm{kg} / \mathrm{m}^{2}\right)$ & $\begin{array}{c}26.16 \\
(24.03,28.03)\end{array}$ & $\begin{array}{c}26.36 \\
(24.31,28.16)\end{array}$ & $\begin{array}{c}26.04 \\
(24.23,28.11)\end{array}$ & $\begin{array}{c}25.81 \\
(23.54,27.86)\end{array}$ & $\begin{array}{c}26.70 \\
(23.71,28.36)\end{array}$ & NS \\
\hline FT3 (pmol/L) & $5.20 \pm 0.71$ & $5.28 \pm 0.93$ & $5.28 \pm 0.61$ & $5.11 \pm 0.51$ & $5.11 \pm 0.72$ & NS \\
\hline FT4 (pmol/L) & $16.49 \pm 2.58$ & $17.05 \pm 3.28$ & $16.90 \pm 2.14$ & $16.23 \pm 2.11$ & $15.76 \pm 2.46 \mathrm{a}, \mathrm{b}$ & 0.001 \\
\hline $\mathrm{TSH}(\mu \mathrm{IU} / \mathrm{mL})$ & $2.23(1.59,2.93)$ & $1.18(0.99,1.42)$ & $1.93(1.75,2.05)$ & $2.53(2.32,2.72)$ & $3.77(3.30,4.67)$ & - \\
\hline Waist circumference (cm) & $92.18 \pm 10.08$ & $92.62 \pm 10.48$ & $92.53 \pm 10.08$ & $90.78 \pm 10.24$ & $92.81 \pm 9.52$ & NS \\
\hline Current smoker, $n(\%)$ & $53(13.9)$ & $19(19.8)$ & $11(11.5)$ & $14(14.6)$ & $9(9.6)$ & NS \\
\hline Diabetes, $n(\%)$ & $10(2.6)$ & $3(3.1)$ & $2(2.1)$ & $3(3.1)$ & $2(2.1)$ & NS \\
\hline Hypertension, $n(\%)$ & $88(23.0)$ & $30(31.3)$ & $23(24.0)$ & $20(20.8)$ & $15(16.0)$ & NS \\
\hline Previous CHD, $n(\%)$ & $41(10.7)$ & $9(9.4)$ & $12(12.5)$ & $6(6.3)$ & $14(14.9)$ & NS \\
\hline Family history of $A D, n(\%)$ & $9(2.4)$ & $1(1.0)$ & $1(1.0)$ & $3(3.1)$ & $4(4.3)$ & NS \\
\hline
\end{tabular}

Continuous variables were compared using one-way ANOVA test or Kruskall-Wallis test and categorical variables by using Chi-squared test. $P<0.05$ was considered significant. Intergroup comparisons were performed using post-hoc Bonferroni test.

a $P<0.05$ vs Quartile $1, \mathrm{~b} P<0.05$ vs Quartile 2.

$A D$, Alzheimer disease; $C H D$, coronary heart disease; FT3, free triiodothyronine; FT4, free thyroxine; TSH, thyroid-stimulating hormone.

\section{Data availability}

Source data are provided or are available from the corresponding author upon reasonable request.

\section{Results}

\section{Low serum TSH level may be a risk factor for cognitive impairment}

To explore the association between TSH level and cognitive impairment, a cross-sectional population study was performed. Cognitive function of the population was evaluated by the score of MMSE, with consideration of the educational achievement of each subject (detailed in Fig. 1B). There was no significant difference in age, FT3 levels, BMI, and waist circumference among the groups divided by TSH quartiles. Rates of smoking, prevalence rate of disease (including diabetes, hypertension, and previous CHD), and family history of $\mathrm{AD}$ were also similar among these groups (Table 2). However, FT4 level was relatively lower in the fourth quartile and gender ratio was also different between groups, which may interfere with investigating the relationship between TSH and the prevalence of cognitive impairment. In order to address this issue, a binary logistic regression analysis was performed with adjustment for potential confounders such as FT4 levels, gender ratios, and so on. Compared with the highest TSH quartile (Quartile 4), the lowest TSH quartile (Quartile 1) displayed approximately 2.1-fold increased risk for cognitive impairment (Table 3). These results indicated that low serum TSH level may be a risk factor for the prevalence of cognitive impairment in human subjects.

\section{Tshr deficiency leads to pronounced deficits in learning and memory tasks}

As TSH is the major endogenous ligand of TSHR and its role dependent on the process of signal transduction of TSHR, it is possible that TSHR signaling may play an essential role in cognitive functions. To test this hypothesis, we first examined the expression of TSHR in murine hippocampus, which is a major component of the brain involved in cognitive functions, especially for spatial learning and memory (Lisman et al. 2017).

Table 3 Logistic regression analysis of TSH quartile and risk for presence of cognitive impairment.

\begin{tabular}{|c|c|c|c|c|}
\hline & $\beta$ & S.E. & OR $(95 \% \mathrm{Cl})$ & $P$ value \\
\hline \multicolumn{5}{|l|}{ TSH quartile } \\
\hline $\begin{array}{l}\text { Quartile } 1 \\
(<1.59 \mu \mathrm{IU} / \mathrm{mL})\end{array}$ & 0.761 & 0.357 & $\begin{array}{c}2.141 \\
(1.063,4.312)\end{array}$ & 0.033 \\
\hline $\begin{array}{l}\text { Quartile } 2 \\
(1.59,2.23 \mu \mathrm{lU} / \mathrm{mL})\end{array}$ & 0.499 & 0.369 & $\begin{array}{c}1.648 \\
(0.800,3.395)\end{array}$ & 0.176 \\
\hline $\begin{array}{l}\text { Quartile } 3 \\
(2.23,2.93 \mu \mathrm{lU} / \mathrm{mL})\end{array}$ & 0.184 & 0.365 & $\begin{array}{c}1.202 \\
(0.588,2.459)\end{array}$ & 0.615 \\
\hline $\begin{array}{l}\text { Quartile } 4 \\
(\geq 2.93 \mu \mathrm{lU} / \mathrm{mL})\end{array}$ & \multicolumn{4}{|c|}{ Reference } \\
\hline
\end{tabular}

Data are coefficient ( $\beta$ ), S.E., odds ratio (OR), 95\% Cl, and significance $(P$ value). Multivariable model for cognitive impairment is adjusted for age, gender, BMI, waist circumference, thyroid hormone, family history of Alzheimer's disease, smoking, present illness of hypertension and diabetes, and previous history of coronary artery disease. 

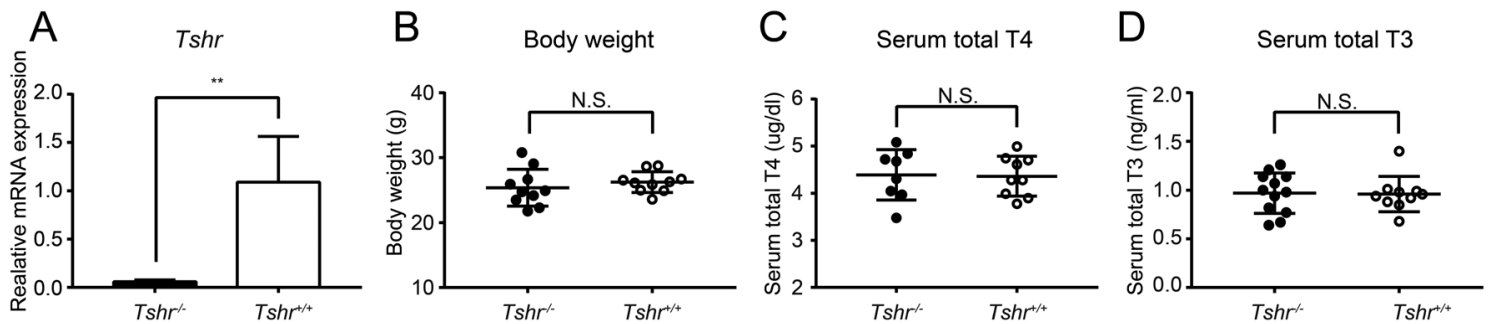

\section{Figure 2}

Expression of Tshr in hippocampus and characterization of Tshr\% mice. (A) Tshr expression was detected in the hippocampus by real-time PCR ( $n=5$ per group). (B) Body weights of Tshr-/- mice and wild-type littermates. (C) Serum total T4 levels of two groups. (D) Serum total T3 levels of two groups. Tshr^-mice were supplemented with thyroid hormone powder ( $n=8-12$ per group). All data are shown as the mean \pm s.D. Student's $t$-test for two-group comparisons. $* * P<0.01$, N.S.: not significant.

Real-time PCR result revealed that TSHR was expressed in the murine hippocampus (Fig. 2A).

To investigate the effect of TSHR signaling on hippocampal function, Tshr was deleted in mice (Fig. 2A). Tshr/- mice were maintained euthyroid using thyroxine powder supplementation. The similar body weights (Fig. 2B) and serum total T4 and T3 levels (Fig. 2C and D) between $T s h r /$ mice and their wild-type littermates demonstrated that the supplementation of thyroxine was appropriate. Spatial learning and memory were examined in the Morris water maze place navigation task. During acquisition training, the latencies to target (Fig. 3B) were increased in Tshr-mice. However, the result of latency could be confounded by the differences in swimming speed between groups (Fig. 3C). The increase in path length, a parameter independent of swimming speed, was also significant, serving as a more reliable sign of spatial learning deficits among Tshr- mice (Fig. 3A). In the probe trial (no platform), Tshr- mice spent significantly less percentage of time in the target quadrant (Fig. 3D) and had significantly fewer target crossings (Fig. 3E). Tshr- mice failed to show a significant preference for the trained target, indicating a spatial reference memory defect. The swimming trace in the probe trial showed that $T s h r^{-}$mice tended to swim aimlessly rather than across the former location of the platform repeatedly (Fig. 3F and G), suggesting their poor performance mainly resulted from hippocampal defects (Per Andersen et al. 2007). To assess their spatial working memory, Y maze was subsequently performed. As detailed path displayed
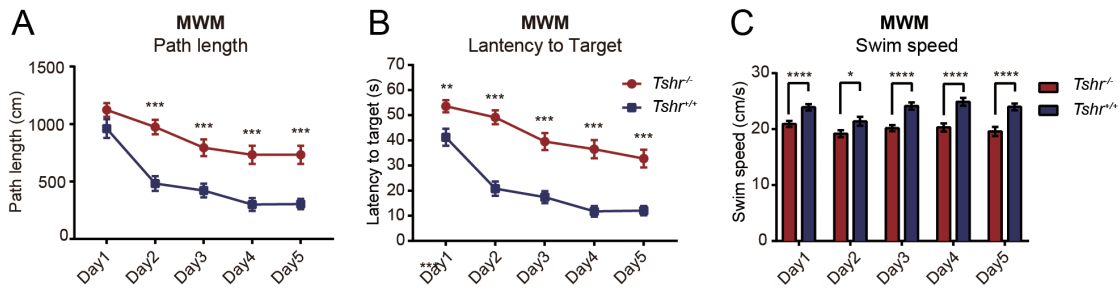
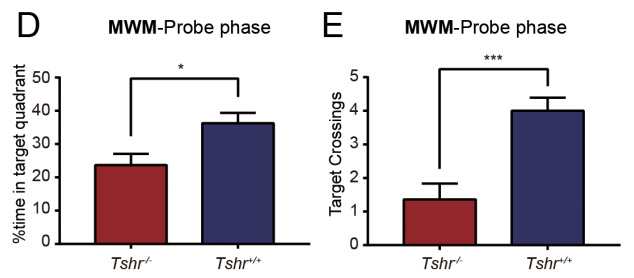

$\mathrm{F}$

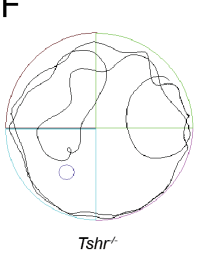

$J$

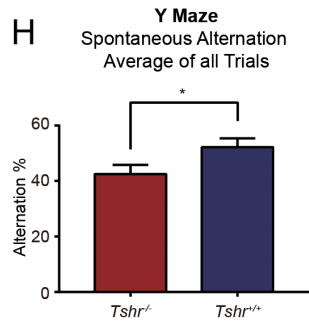

\section{I} Y Maze
Number of Entries

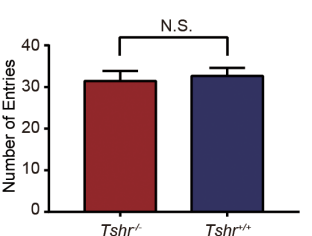

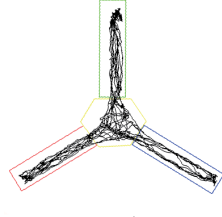

Tshr'
G

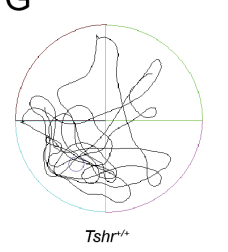

K

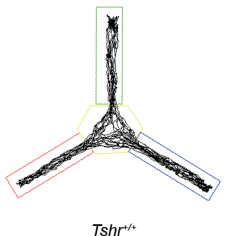

Figure 3

Tshr/- mice showed pronounced deficits in learning and memory tests. (A, B, and C) Swim path length $(A)$, latency to target $(B)$, and swim speed $(C)$ of place navigation in the Morris water maze (MWM). ( $D$ and $E$ ) Percentage of time spent in target quadrant (D), the number of crosses over the region where the platform was formerly located (E) in probe trial (the platform was removed) $24 \mathrm{~h}$ after the last acquisition day. ( $F$ and $G$ ) Representative tracings from the MWM probe trial of Tshr/- mice (F) and wild-type littermates $(\mathrm{G})$. ( $\mathrm{H}$ and $\mathrm{I}$ ) The number of arm entries $(H)$, the percentage of spontaneous alternation behavior (I) in the $\mathrm{Y}$ maze. ( $\mathrm{I}$ and $\mathrm{K}$ ) Representative traces in the $Y$ maze showing the path of $T s h r \%$ mice $(\mathrm{J})$ and wild-type littermates (K), respectively. $n=11$ Tshr/ mice, $n=12$ wild-type littermates. All data are shown as the mean \pm S.E.M. Student's $t$-test for two-group comparisons. ${ }^{\star} P<0.05 ;{ }^{*} p<0.01 ; * \star \star * P<0.001$. N.S.: not significant. https://joe.bioscientifica.com https://doi.org/10.1530/JOE-20-0026
(C) 2020 Society for Endocrinology Published by Bioscientifica Ltd.
Printed in Great Britain 
(Fig. 3J and K), Tshr- mice showed significantly reduced percentage of spontaneous alteration (Fig. $3 \mathrm{H}$ ) and no significant difference in the number of arm entries (Fig. 3I) compared with wild-type littermates. Taken together, Tshr deficiency led to impaired spatial reference and working memory.

\section{$T s h r^{\prime-~ m i c e ~ d i s p l a y e d ~ r e d u c e d ~ e x c i t a t o r y ~ s y n a p t i c ~}$ density and altered synaptic structure}

To figure out neuroanatomical changes underlying impaired behavioral performance in Tshr/ mice, histological analysis of hippocampus was performed. Nissl staining on serial brain sections (interval $360 \mu \mathrm{m}$ ) showed that there was no alternation in the gross morphology of hippocampus in Tshr/ mice and wild-type littermates at corresponding coronal levels (Fig. 4A and C). Moreover, neuron-specific antigen NeuN expression (Fig. 4B) also revealed no significant difference in the number of NeuN+ cells in DG, CA1, and CA2/3 subfields of hippocampus (Fig. 4D, E and F). Overall, the hippocampus of Tshr/- mice and their littermates have similar anatomical features and equivalent number of mature neurons.

It is well established that spine morphology and density are linked to synaptic function in the hippocampal CA1 region, an area crucial for spatial memory (Tsien et al. 1996). We then observed the number of dendritic spines of CA1 pyramidal neurons. Spine densities of apical and basal dendritic segments in pyramidal neurons reduced dramatically in Tshr mice when compared to their littermates (Fig. 5A, B and C). As dendritic spines are the anatomic structures possessing the most excitatory synapses (Alvarez \& Sabatini 2007), the asymmetric (excitatory) synapses of hippocampus sections were further studied by direct observation under transmission electron microscopy (Fig. 5D). Consistent with the results of Golgi staining, a significant reduction in excitatory synapse density was observed in the CA1 subfield of the hippocampus of $T s h r$ mice compared to their littermates (Fig. 5E). Perforated synapses density, an indicator of synaptic activeness (Neuhoff et al. 1999), was also reduced in $T s h r$ mice when quantified as absolute count (Fig. 5F). In addition, significant structural alterations were observed in the postsynaptic density (PSD) width (Fig. 5H), synaptic cleft (Fig. 5I) of Tshr-mice, but no difference was found in presynaptic terminal area, terminal perimeter, or the number of vesicles per terminal between the two genotypes (Fig. 5J and K). In summary, the density and structure of excitatory of synapse altered by TSHR signaling deficiency may cause the cognitive defect.

\section{Synapse-related gene expression profile was altered in the $T s h r /$ mice hippocampus}

To determine the underlying molecular mechanism of the spatial learning and memory deficits caused by $T s h r$ deletion, the hippocampal gene expression profile of Tshrmice and wild-type littermates were examined by RNASeq. A total of 438 DEGs were revealed by the DESeq2, including 188 upregulated genes and 250 downregulated genes in the hippocampus tissue of Tshr- mice compared to their littermates (Fig. 6A). Gene transcriptional profile of $\mathrm{Tshr}^{\mathrm{N}}$ mice were completely different from their littermates, as the two groups were well separated by the first three principal components (Fig. 6B). KEGG pathways (Fig. 6C) and GO enrichment analysis (Fig. 6D) were then performed by ClusterProfiler R package. The top of the significant terms identified in both KEGG pathway and GO enrichment analysis were synapse-related component and signaling, including glutamatergic synapse, dopaminergic synapse, and serotonergic synapse, which were known to be crucially involved in the function of learning and memory. The alternation of hippocampal synapserelated gene expression is at least, in part, responsible for behavioral defect and synaptic structure in Tshr/ mice.

Additionally, PPI and module analysis of DEGs were performed by STRING and Cytoscape, respectively (Fig. 6E). A deal of top ten hub genes, the center of the distribution of node degrees, are synaptic plasticity-related genes. The changes of those DEGs were confirmed by real-time PCR. Consistent with RNA-Seq results, the mRNA levels of Egr1, Junb, Egr2, Arc, Fos, Bdnf, and Naps4 were significantly downregulated in Tshr- mice hippocampus (Fig. 6F).

Among the hub genes in our transcriptomic analysis (Fig. 6E), Bdnf, Egr1, and Fos genes were in the topsignaling network and required for learning and memory. We subsequently quantified the protein expression of phosphorylation of CREB (pCREB), the brain-derived neurotrophic factor (BDNF), and immediate early genes (IEGs). pCREB level is significantly diminished in DG, CA1, and CA3 subfields of Tshr/- mice hippocampus, revealed by immunohistochemistry (Fig. 7A, B, C and D). The expression of BDNF was decreased significantly in Tshr mice hippocampus (Fig. 7E and F). The immunohistochemistry of EGR1 (Fig. 7G) and FOS (Fig. $7 \mathrm{H})$ demonstrated that the number of FOS-positive cells were significantly reduced in CA1, CA3, and DG subfields (Fig. 7I, J and K), while the number of EGR1-positive cells showed a remarkable reduction in CA3 and DG subfields, but not CA1 region in Tshr-mice hippocampus (Fig. 7L and N). Taken together, these data suggest that 
A cognitive function
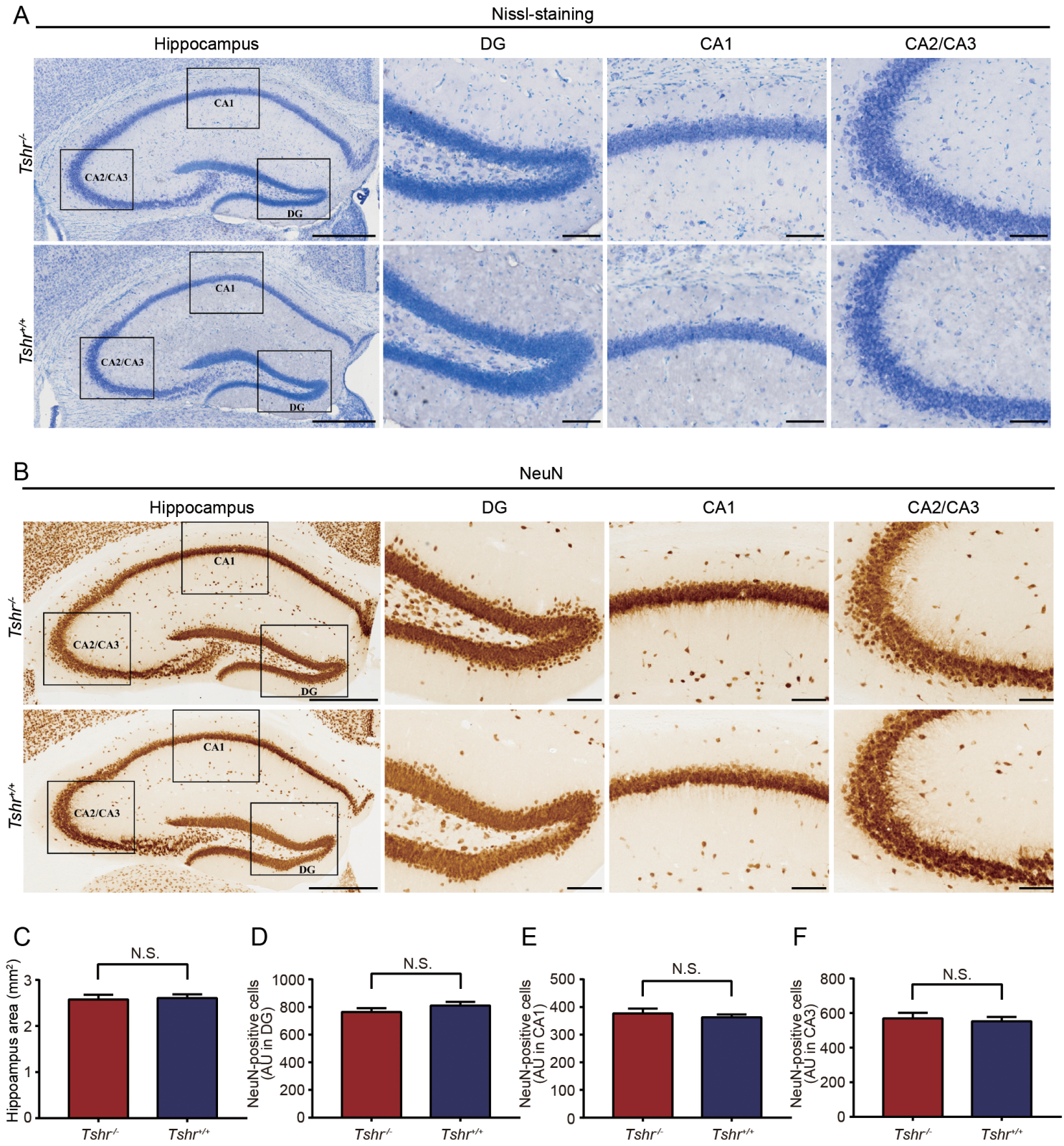

D

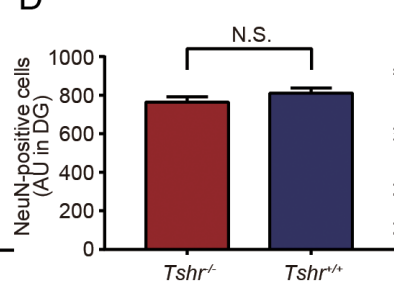

E

F
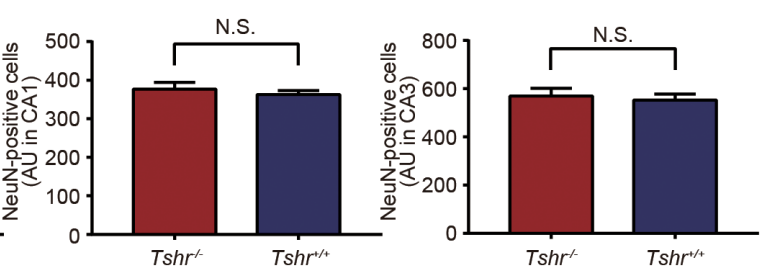

\section{Figure 4}

No significant difference of morphology in hippocampus was detected in Tshr $\%$ mice by Nissl and NeuN staining. (A) Representative images of Nissl staining in hippocampus. (B) Immunohistochemical representation of NeuN in hippocampus. (C) Quantification of hippocampal area. (D, E, and F) Quantification of the immunostaining for NeuN in the DG (D), CA1 (E), and CA3 (F) subfields. Scale bars: $500 \mu \mathrm{m}$ (low magnification); $100 \mu \mathrm{m}$ (high magnification). Arbitrary Unit (AU): $0.3 \mathrm{~mm}^{2}$. Four sections per mouse were analyzed. Quantitative analysis was performed using HistoQuest software. All data are shown as the mean \pm S.E.M. Student's $t$-test for two-group comparisons. ${ }^{*} P<0.05 ; * \star p<0.01 ; * \star \star p<0.001$. N.S.: not significant. ( $n=4$ per group.)

the alternation of synapse-related gene expression might induce cognitive defect in Tshr mice.

\section{Discussion}

In this study, we provide clear evidence that TSHR signaling deficiency in the mice resulted in remarkably impaired spatial learning and memory, accompanied by reduction in dendritic spine density, alteration in the density and structure of excitatory synapses in CA1 pyramidal neurons, and significantly diminished CREB activation and synapserelated gene transcription. Thus, our study demonstrates an essential role of TSHR signaling in cognitive function.

The association between low TSH level and dementia or mild cognitive impairment has been disclosed by 
A

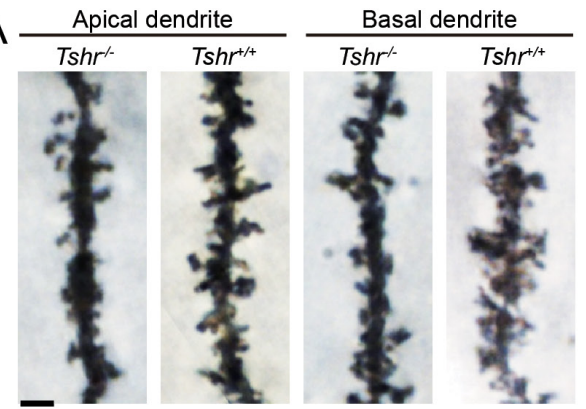

B

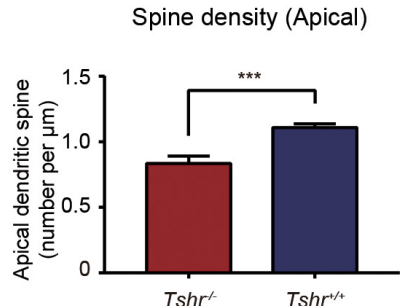

E

D
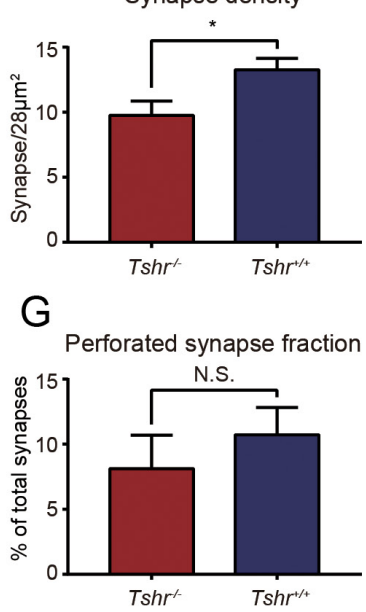

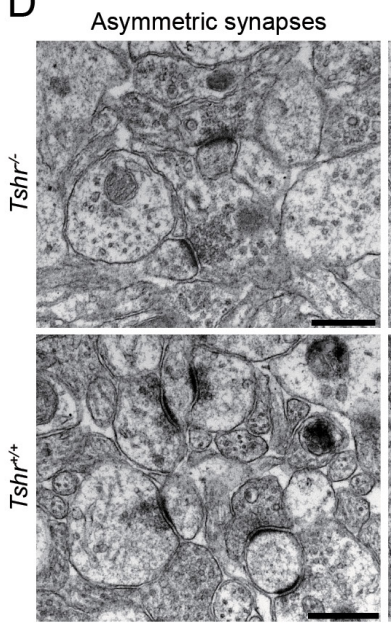

Perforated synapses

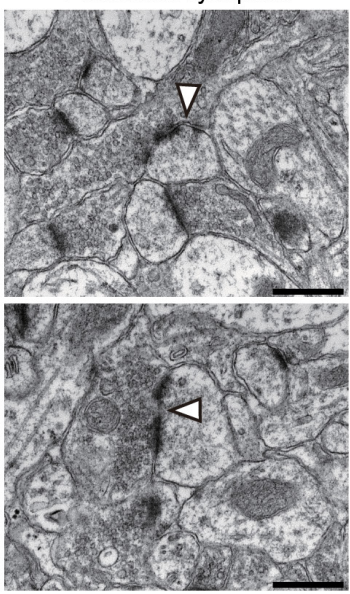

J
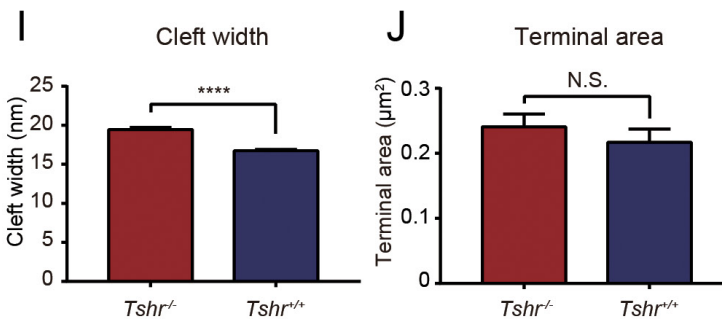

F
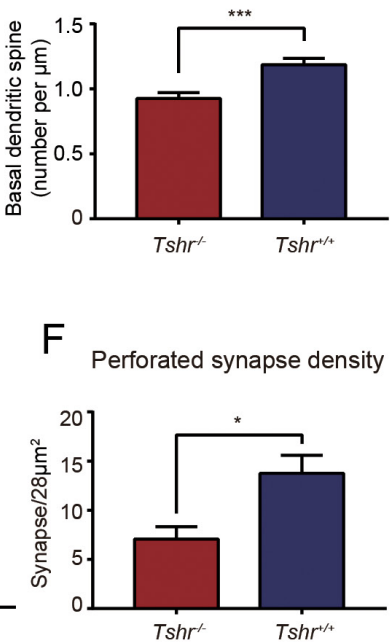

$\mathrm{H}$
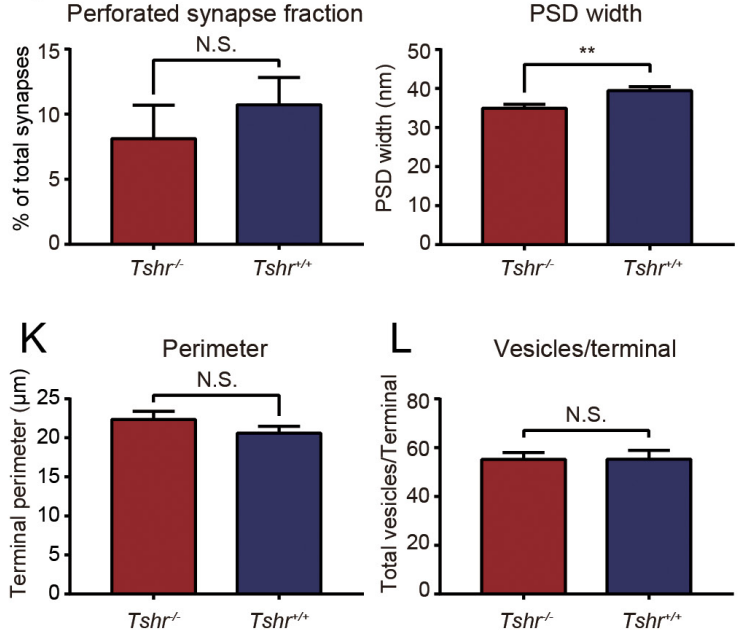

\section{Figure 5}

Golgi staining and electron microscopy revealed decreased dendritic spines density, asymmetric synaptic density, and altered synaptic structure in the CA1 subfield of Tshr/ mice hippocampus. (A) Representative Golgi staining images of apical and basal dendritic spines in the hippocampus of Tshr/ mice and wild-type littermates, focusing on the CA1 subfield. (B and C) Summary graph of apical (B) and basal (C) dendritic spine density. Scale bars: $2 \mu \mathrm{m}$. Data are from 20 apical/20 basal dendrites for each genotype. Quantitative analysis was performed using Image software. (D) Representative images of asymmetric synapses and perforated asymmetric synapses in hippocampus of Tshr-/ mice and their littermates, focusing on the CA1 subfield. Arrowheads point to the gap in the perforated postsynaptic density. (E) Summary graph of the density of asymmetric synapses. (F and G) Summary graphs of the density of perforated synapses (F), and fraction of total synapses (G) that were perforated. (H, I, J, K, and L) Summary graphs of PSD width $(\mathrm{H})$, width of the synaptic cleft (I), presynaptic terminal area $(\mathrm{J})$, presynaptic terminal perimeter (K), and number of presynaptic vesicles per terminal (L). Scale bars: $500 \mathrm{~nm}$. Quantitative analysis was performed using ImageJ Pro Plus software. All data are shown as the mean \pm s.E.m. Student's $t$-test for two-group comparisons. ${ }^{*} P<0.05 ; * \star P<0.01 ; * \star \star * P<0.001$. N.S.: not significant. ( $n=4$ per group).

several clinical studies (Kim et al. 2010, Aubert et al. 2017). In this study, low serum TSH level may be a risk factor for the prevalence of cognitive impairment, which is consistent with the result of a large-scale observational study including more than 10,000 subjects (Szlejf et al. 2018). Conversely, Kumar et al. utilizing cutting-edge in vivo imaging technique reported significantly impaired cognition in subclinical hypothyroidism (SCH) patients (Kumar et al. 2018). This discrepancy might be due to the difference in the subjects that were included between the studies. In Kumar et al. study, the TSH level of SCH group is $9.61 \pm 1.39 \mu \mathrm{IU} / \mathrm{mL}$, which is much higher than that of our research. Even in the highest TSH quartile group of our study, the TSH level was $3.77(3.30,4.67) \mu \mathrm{IU} / \mathrm{mL}$ 
A

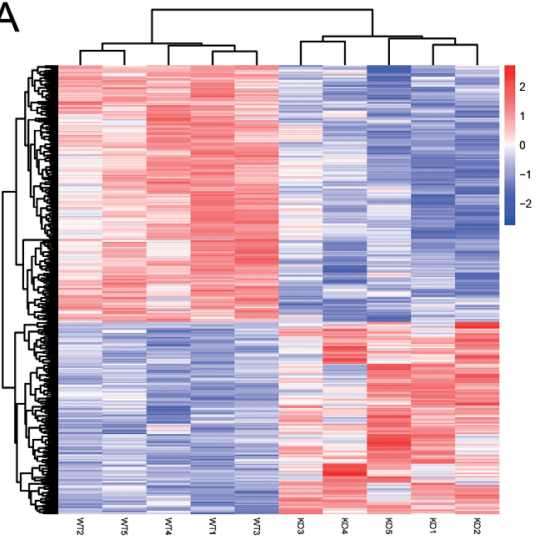

D

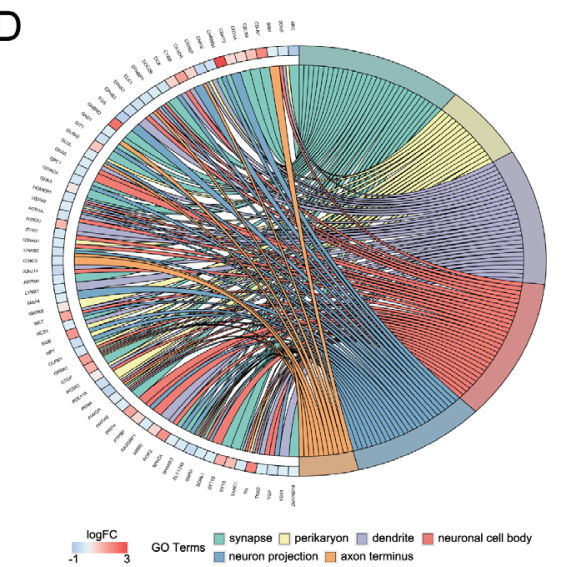

B

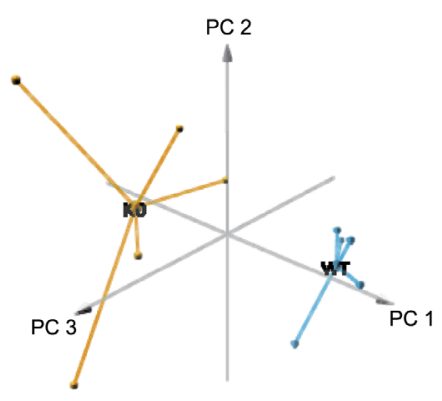

E

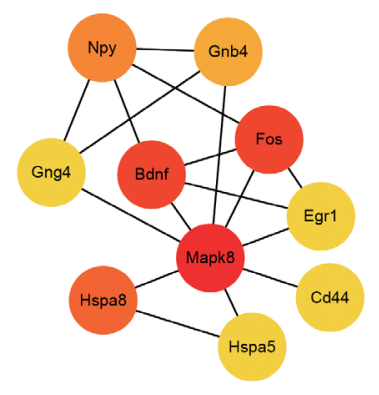

C

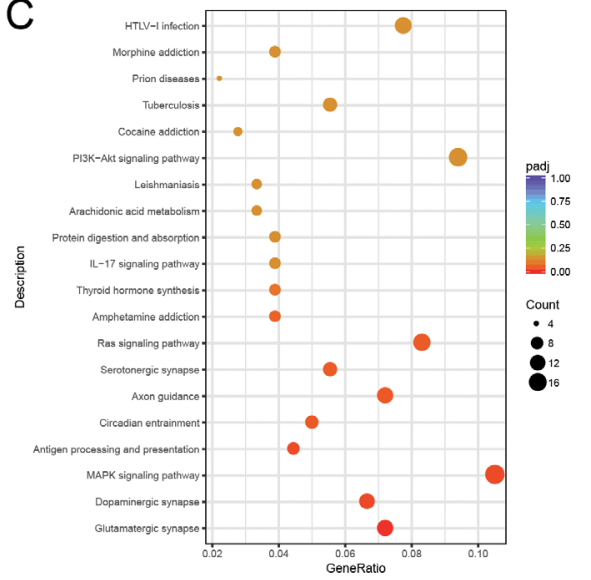

F

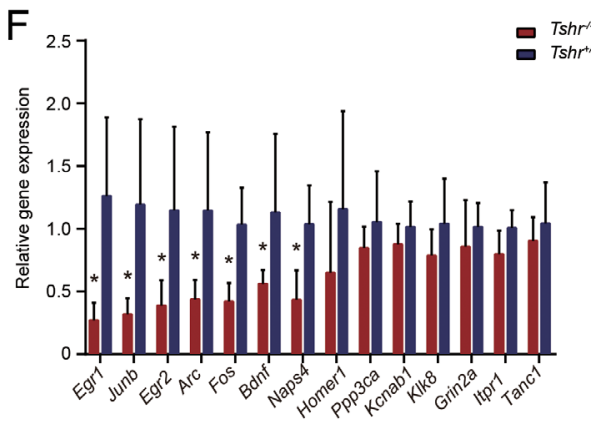

\section{Figure 6}

Transcriptomic analysis identified that the synapse-related gene expression profile was altered in Tshr-mice hippocampus. (A) Heat map showing clustered gene changes in the hippocampus of Tshr- mice and wild-type littermates. (color bar represents Z-score range; $P<0.05$ ). (B) 3D plot of the first three components from principal component analysis of RNA sequencing. (C) KEGG pathway analysis of differentially expressed genes (DEGs) between Tshr/- mice and their littermates. Size and color of the bubble represent amount of DEGs enriched in the pathway and enrichment significance, respectively. (D) The top GO terms of Chord plot of DEGs between Tshr/ mice and their littermates. Blue-to-red coding next to the selected genes indicates logFC. (E) Identification of hub genes from the PPI network. The node color changes from yellow to red in ascending order according to log2FC. (F) Relative synapse-related genes expression was examined by real-time PCR ( $n=5$ per group), and the data are shown as the mean \pm s.D. $* P<0.05$.

and most of the subjects were non-SCH. Moreover, even though their study suggested abnormally high TSH level to be deleterious to cognitive function, the potential interference of decreased thyroid hormones should be considered, because markedly increased TSH level associates with decreased thyroid function. The impaired cognition observed among subclinical hypothyroidism patients may likely be a result of relatively declined thyroid hormones activity rather than a potentially detrimental effect of high TSH level on the neural system. On the contrary, most of our subjects have normal TSH, FT3, and FT4 levels. Despite the differences of FT4 levels between groups, thyroid hormones failed to enter the model in our study with statistical significance $(P>0.05)$ either adjusted as binary or continuous variables. Therefore, comparing with FT4, it is likely that TSH plays a relatively important

(C) 2020 Society for Endocrinology Published by Bioscientifica Ltd.
Printed in Great Britain role in cognitive function in a population with normal thyroid function.

To date, the role of TSH signal transduction in brain function remains unclear. To address the issue, we utilized $T s h r$ knockout mice models and found that TSHR signaling deficiency led to impaired performance in spatial learning and memory tasks. Our study shows an essential role of TSHR signaling in cognitive function and extends the understanding of TSHR physiological role in neuroendocrinology. Similarly, Akihiro Mouri and colleagues demonstrated that TSHR knockout in mice led to behavioral and neurological phenotypes of attention deficit hyperactivity disorder (ADHD) related to monoaminergic nervous systems (Mouri et al. 2014). Nevertheless, in their study, the thyroid hormone replacement therapy diet placed on TSHR knockout mice 
B

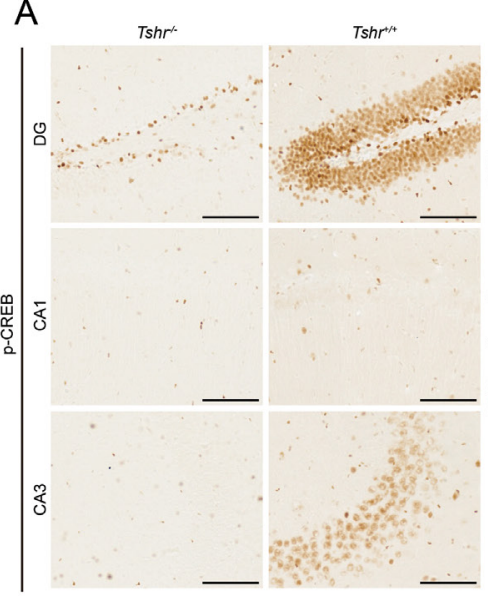

G

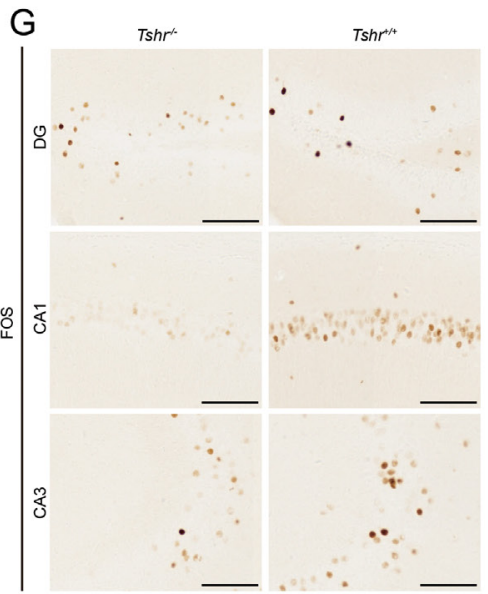

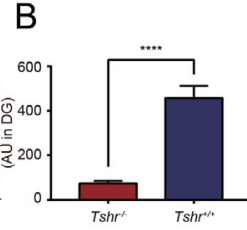

C

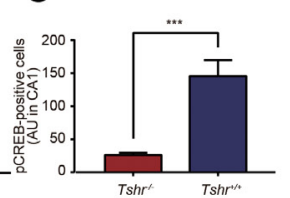

E
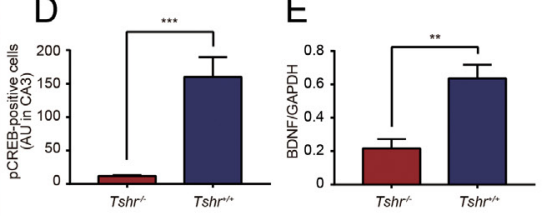

$\mathrm{F}$

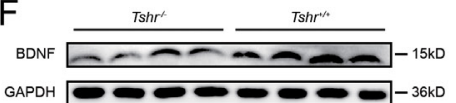

$\mathrm{H}$

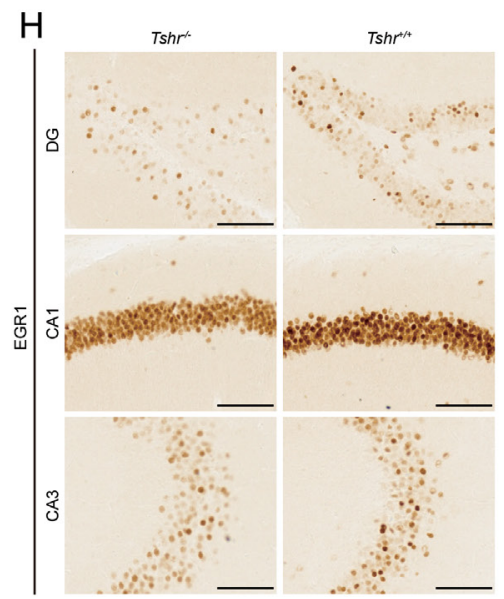

I

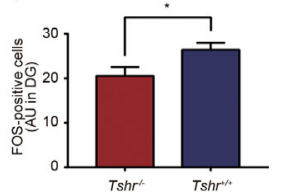

K

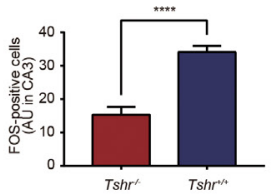

M

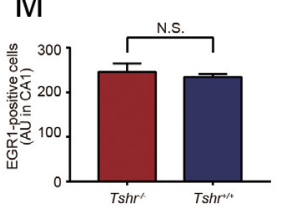

$\mathrm{J}$

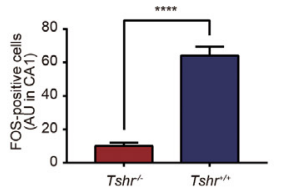

L

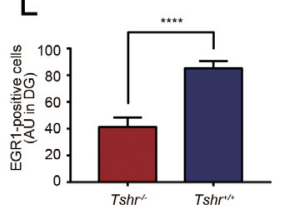

N

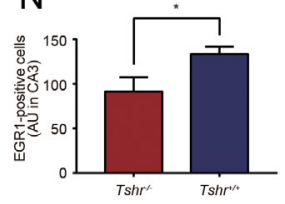

Figure 7

Tshr knockout induced downregulated p-CREB, BDNF, and immediate early gene expression in hippocampus. (A) Immunohistochemical representation of p-CREB in hippocampus. (B, C, and D) Quantification of the immunostaining for p-CREB in the DG (B), CA1 (C), and CA3 (D) subfields. (E and F) BDNF protein level was examined in hippocampus by immunoblotting. (G and H) Immunohistochemical representation of FOS and EGR1 in hippocampus. (I, J, and K) Quantification of the immunostaining for FOS in the DG (I), CA1 (J), and CA3 (K) subfields. (L, M, and N) Quantification of the immunostaining for EGR1 in the DG (L), CA1 (M), and CA3 (N) subfields. Scale bars: $100 \mu \mathrm{m}$. Arbitrary Unit (AU): $0.3 \mathrm{~mm}^{2}$. Four sections per mouse were analyzed ( $n=3$ or 4 per group). Quantitative analysis was performed using HistoQuest software. All data are shown as the mean \pm S.E.M. Student's $t$-test for two-group comparisons. ${ }^{*} P<0.05 ; * * P<0.01 ; * \star * P<0.001$. N.S.: not significant.

was stopped 1 week before the behavior test. Therefore, their data is unable to rule out the contribution of thyroid hormone deficiency in brain functions. In contrast, we did not cease the thyroid hormone supplementation and euthyroidism was maintained among the mice throughout the behavioral tests. Importantly, we emphasized on the role of TSHR signaling on the spine density, synaptic morphology, and gene expression change in hippocampus, which are crucially involved in spatial learning and memory.

In this study, multiple synaptic changes can account for the alteration in the impairment of learning and memory ability observed in Tshr mice. Decreased dendritic spine density of hippocampal CA1 pyramidal neuron was observed in Tshr/- mice compared to wild- type littermates. Dendritic spines, as the biochemical and electrical compartments within neurons, are the sites of excitatory synaptic contact closely related to the information processing that underlies cognition. New spine growth, maturation, and stabilization/pruning are reciprocally regulated by neuronal activity and different signaling pathways, which are essential for learning and memory (Kasai et al. 2010). Abnormal dendritic spine density leads to alternation in synaptic strength and thereby changes the cognitive function of mice.

The number of dendritic spines correlates strongly with the number of excitatory synapses in hippocampus pyramidal neurons (Nimchinsky et al. 2004), not surprisingly, a significant reduction in excitatory synapse density was observed by electron microscope in the CA1 
subfield of the hippocampus of Tshr-mice. The perforated synapses density also decreased in hippocampal CA1 subfield. Perforated synapses are morphologically characterized by a discontinuity in the PSD, an electrondense web beneath the postsynaptic membrane, and substantial evidence points to their important role in memory-related plasticity and recognition memory accuracy (Toni et al. 2001, Hara et al. 2012). Additionally, a series of ultrastructural changes in the hippocampal synapses of Tshr- mice were discovered, including the decrease in PSD thickness and the increase in synaptic cleft width. PSD is composed of a variety of proteins responsible for the clustering and transport of membranebound receptors, the temporal and spatial organization of signaling cascades, the dynamic organization of cytoskeletal components, and the induction and structural maintenance of intercellular contact sites (Boeckers 2006). The thickness of PSD reflects to some extent the amount of protein that made up this structure. Therefore, a significantly decreased PSD thickness is indicative of alterations in postsynaptic synaptic assembly and signaling. On the other hand, synaptic cleft, a narrow space between pre- and postsynaptic membrane, contains trans-synaptic complexes that form extensive lateral connections (Zuber et al. 2005). As the size of cleft determines how quickly secreted neurotransmitters reach the postsynaptic membrane, widened synaptic clefts may influence the neurotransmitter transmission between neurons.

CREB plays key roles in the regulation of synaptic transmission efficacy and synaptic growth and is essential to learning activity and memory formation (Kandel et al. 2014, Lisman et al. 2018). Ser-133 phosphorylation of CREB, which is critical for its transcriptional activating activity, was affected by Tshr deletion. Meanwhile, the mRNA and protein levels of plasticity-related genes were shown to be significantly reduced in our transcriptomic analysis, PCR analysis, and biochemical analysis of Tshr\% hippocampal tissue. Among these genes, BDNF stands out for its high level of expression in the brain and its potent effect on synapses. BDNF has short-term and long-lasting effect on the synapses, depending on the dominant downstream signaling cascades on synapses ( $\mathrm{Lu}$ et al. 2014). Notably, BDNF plays a critical role in hippocampal long-term potentiation, an enhancement of synaptic efficacy thought to underlie learning and memory (Minichiello 2009). As for IEGs, evidence has shown a key role of Egr1 in hippocampal functions with an increasing sensitivity to Egr1 deficiency as the complexity and the explicit spatial demand of the task increase (Jones et al.
2001). Arc, involved in synaptogenesis and synapse maintenance, is necessary for various forms of synaptic plasticity and is critical for information storage and cognition (Korb \& Finkbeiner 2011). Fos, despite the fact that its role at the cellular level is more complex than for other IEGs, is crucial in hippocampus-dependent spatial and associative learning tasks (Fleischmann et al. 2003). This indicated that downregulated synapse-related genes may be the central target for the alternation of synaptic structure and function caused by TSHR signaling deficiency.

Nevertheless, besides hippocampus, TSHR is expressed in multiple brain regions and organs. Cognition is a complex cortical activity that is coordinated by various cell types in multiple brain regions (Klausberger \& Somogyi 2008, Santello et al. 2019). Even though remarkable structural and molecular changes were observed in the hippocampus of the Tshr- mice, the present study did not define the role of TSHR signaling in specific cell types in hippocampus. Moreover, it cannot be ruled out that hippocampal neurogenesis or other brain regions might be involved in the induction of cognitive defects in the Tshr $\%$ mice. Therefore, more delicate investigations are required for a complete understanding of the role of TSHR signaling in cognitive function.

In conclusion, our results demonstrate that TSHR signaling deficiency leads to impaired spatial learning and memory, accompanied by hippocampal defects at the structural and molecular level. These findings provide new knowledge about the neurologic significance of TSHR signaling and may be helpful for the pathophysiology and clinical practice of subclinical hyperthyroidism.

\section{Declaration of interest}

The authors declare that there is no conflict of interest that could be perceived as prejudicing the impartiality of the research reported.

\section{Funding}

This work was supported by the National Key Research and Development Program of China (grant number 2017YFC1309800) and the National Natural Science Foundation of China (grant number 81430020, 31471321).

\section{Author contribution statement}

J) $Z$ defined the research theme. $Z \mathrm{H}, \mathrm{XH}, \mathrm{L} \mathrm{G}$, and Y F D guided the research experiments and writing. S S L, W K B, S L H, and J J collected the clinical data. S S L, L P, and Z B L performed experiments. S S L performed data analysis and wrote the manuscript. 


\section{Acknowledgements}

The authors thank professors Lin Li and Bo Meng for their insightful comments. Meanwhile, the authors appreciate the staff of TISSUEGNOSTICS ASIA PACIFIC LTD. for their assistance in image acquisition and analysis. The authors also thank Adriana C Panayi for the language editing and Zixing Wang for statistical analysis.

\section{References}

Abe E, Marians RC, Yu W, Wu XB, Ando T, Li Y, Iqbal J, Eldeiry L, Rajendren G, Blair HC, et al. 2003 TSH is a negative regulator of skeletal remodeling. Cell 115 151-162. (https://doi.org/10.1016/ s0092-8674(03)00771-2)

Alvarez VA \& Sabatini BL 2007 Anatomical and physiological plasticity of dendritic spines. Annual Review of Neuroscience 30 79-97. (https://doi. org/10.1146/annurev.neuro.30.051606.094222)

Aubert CE, Bauer DC, da Costa BR, Feller M, Rieben C, Simonsick EM, Yaffe K, Rodondi N \& Health ABC Study 2017 The association between subclinical thyroid dysfunction and dementia: the Health, Aging and Body Composition (Health ABC) study. Clinical Endocrinology 87 617-626. (https://doi.org/10.1111/cen.13458)

Biondi B \& Cooper DS 2008 The clinical significance of subclinical thyroid dysfunction. Endocrine Reviews 29 76-131. (https://doi. org/10.1210/er.2006-0043)

Boeckers TM 2006 The postsynaptic density. Cell and Tissue Research $\mathbf{3 2 6}$ 409-422. (https://doi.org/10.1007/s00441-006-0274-5)

Cianfarani F, Baldini E, Cavalli A, Marchioni E, Lembo L, Teson M, Persechino S, Zambruno G, Ulisse S, Odorisio T, et al. 2010 TSH receptor and thyroid-specific gene expression in human skin. Journal of Investigative Dermatology 130 93-101. (https://doi.org/10.1038/ jid.2009.180)

Crum RM, Anthony JC, Bassett SS \& Folstein MF 1993 Populationbased norms for the mini-mental state examination by age and educational level. JAMA 269 2386-2391. (https://doi.org/10.1001/ jama.1993.03500180078038)

Davies T, Marians R \& Latif R 2002 The TSH receptor reveals itself. Journal of Clinical Investigation 110 161-164. (https://doi.org/10.1172/ JCI16234)

Fleischmann A, Hvalby O, Jensen V, Strekalova T, Zacher C, Layer LE, Kvello A, Reschke M, Spanagel R, Sprengel R, et al. 2003 Impaired long-term memory and NR2A-type NMDA receptordependent synaptic plasticity in mice lacking c-Fos in the CNS Journal of Neuroscience 23 9116-9122. (https://doi.org/10.1523/ JNEUROSCI.23-27-09116.2003)

Gan EH \& Pearce SH 2012 Clinical review: the thyroid in mind: cognitive function and low thyrotropin in older people. Journal of Clinical Endocrinology and Metabolism 97 3438-3449. (https://doi.org/10.1210/ jc.2012-2284)

Gothie JD, Vancamp P, Demeneix B \& Remaud S 2020 Thyroid hormone regulation of neural stem cell fate: from development to ageing. Acta Physiologica 228 e13316. (https://doi.org/10.1111/apha.13316)

Hara Y, Park CS, Janssen WG, Roberts MT, Morrison JH \& Rapp PR 2012 Synaptic correlates of memory and menopause in the hippocampal dentate gyrus in rhesus monkeys. Neurobiology of Aging 33 421.e17-421.e28. (https://doi.org/10.1016/j. neurobiolaging.2010.09.014)

Hojvat S, Baker G, Kirsteins L \& Lawrence AM 1982 TSH in the rat and monkey brain. Distribution, characterization and effect of hypophysectomy. Neuroendocrinology 34 327-332. (https://doi. org/10.1159/000123322)

Jones MW, Errington ML, French PJ, Fine A, Bliss TV, Garel S, Charnay P, Bozon B, Laroche S \& Davis S 2001 A requirement for the immediate early gene Zif268 in the expression of late LTP and long-term memories. Nature Neuroscience 4 289-296. (https://doi. org/10.1038/85138)

Kandel ER, Dudai Y \& Mayford MR 2014 The molecular and systems biology of memory. Cell 157 163-186. (https://doi.org/10.1016/j. cell.2014.03.001)

Kasai H, Fukuda M, Watanabe S, Hayashi-Takagi A \& Noguchi J 2010 Structural dynamics of dendritic spines in memory and cognition. Trends in Neurosciences 33 121-129. (https://doi.org/10.1016/j. tins.2010.01.001)

Katzman R, Zhang MY, Ouang Ya Q, Wang ZY, Liu WT, Yu E, Wong SC, Salmon DP \& Grant I 1988 A Chinese version of the mini-mental state examination; impact of illiteracy in a Shanghai dementia survey. Journal of Clinical Epidemiology 41 971-978. (https://doi. org/10.1016/0895-4356(88)90034-0)

Kim JM, Stewart R, Kim SY, Bae KY, Yang SJ, Kim SW, Shin IS \& Yoon JS 2010 Thyroid stimulating hormone, cognitive impairment and depression in an older Korean population. Psychiatry Investigation 7 264-269. (https://doi.org/10.4306/pi.2010.7.4.264)

Klausberger T \& Somogyi P 2008 Neuronal diversity and temporal dynamics: the unity of hippocampal circuit operations. Science $\mathbf{3 2 1}$ 53-57. (https://doi.org/10.1126/science.1149381)

Korb E \& Finkbeiner S 2011 Arc in synaptic plasticity: from gene to behavior. Trends in Neurosciences 34 591-598. (https://doi. org/10.1016/j.tins.2011.08.007)

Kumar M, Modi S, Rana P, Kumar P, Kanwar R, Sekhri T, D'Souza M \& Khushu S 2018 Alteration in intrinsic and extrinsic functional connectivity of resting state networks associated with subclinical hypothyroid. Journal of Neuroendocrinology 30 e12587. (https://doi. org/10.1111/jne.12587)

Lalonde R 2002 The neurobiological basis of spontaneous alternation. Neuroscience and Biobehavioral Reviews 26 91-104. (https://doi. org/10.1016/s0149-7634(01)00041-0)

Lisman J, Buzsaki G, Eichenbaum H, Nadel L, Ranganath C \& Redish AD 2017 Viewpoints: how the hippocampus contributes to memory, navigation and cognition. Nature Neuroscience 20 1434-1447. (https:// doi.org/10.1038/nn.4661)

Lisman J, Cooper K, Sehgal M \& Silva AJ 2018 Memory formation depends on both synapse-specific modifications of synaptic strength and cell-specific increases in excitability. Nature Neuroscience $\mathbf{2 1}$ 309-314. (https://doi.org/10.1038/s41593-018-0076-6)

Lopez-Juarez A, Remaud S, Hassani Z, Jolivet P, Pierre Simons J, Sontag T, Yoshikawa K, Price J, Morvan-Dubois G \& Demeneix BA 2012 Thyroid hormone signaling acts as a neurogenic switch by repressing Sox2 in the adult neural stem cell niche. Cell Stem Cell 10 531-543. (https:// doi.org/10.1016/j.stem.2012.04.008)

Lu B, Nagappan G \& Lu Y 2014 BDNF and synaptic plasticity, cognitive function, and dysfunction. Handbook of Experimental Pharmacology 220 223-250. (https://doi.org/10.1007/978-3-642-45106-5_9)

Marians RC, Ng L, Blair HC, Unger P, Graves PN \& Davies TF 2002 Defining thyrotropin-dependent and -independent steps of thyroid hormone synthesis by using thyrotropin receptor-null mice. PNAS 99 15776-15781. (https://doi.org/10.1073/pnas.242322099)

Minichiello L 2009 TrkB signalling pathways in LTP and learning. Nature Reviews: Neuroscience 10 850-860. (https://doi.org/10.1038/nrn2738)

Mouri A, Hoshino Y, Narusawa S, Ikegami K, Mizoguchi H, Murata Y, Yoshimura T \& Nabeshima T 2014 Thyrotoropin receptor knockout changes monoaminergic neuronal system and produces methylphenidate-sensitive emotional and cognitive dysfunction. Psychoneuroendocrinology 48 147-161. (https://doi.org/10.1016/j. psyneuen.2014.05.021)

Naicker M \& Naidoo S 2018 Expression of thyroid-stimulating hormone receptors and thyroglobulin in limbic regions in the adult human brain. Metabolic Brain Disease 33 481-489. (https://doi.org/10.1007/ s11011-017-0076-3)

Neuhoff H, Roeper J \& Schweizer M 1999 Activity-dependent formation of perforated synapses in cultured hippocampal neurons. European https://joe.bioscientifica.com

https://doi.org/10.1530/JOE-20-0026 (c) 2020 Society for Endocrinology Published by Bioscientifica Ltd. Printed in Great Britain 
Journal of Neuroscience 11 4241-4250. (https://doi.org/10.1046/j.14609568.1999.00856.x)

Nimchinsky EA, Yasuda R, Oertner TG \& Svoboda K 2004 The number of glutamate receptors opened by synaptic stimulation in single hippocampal spines. Journal of Neuroscience 24 2054-2064. (https:// doi.org/10.1523/JNEUROSCI.5066-03.2004)

Ning G \& Reaction Study Group 2012 Risk Evaluation of cAncers in Chinese diabeTic Individuals: a lONgitudinal (REACTION) study. Journal of Diabetes 4 172-173. (https://doi.org/10.1111/j.17530407.2012.00182.x)

Noguchi T, Sugisaki T, Satoh I \& Kudo M 1985 Partial restoration of cerebral myelination of the congenitally hypothyroid mouse by parenteral or breast milk administration of thyroxine. Journal of Neurochemistry 45 1419-1426. (https://doi. org/10.1111/j.1471-4159.1985.tb07208.x)

Per Andersen RM, Amaral D, Bliss T \& O'Keefe J 2007 The hippocampus book. In The Hippocampus Book, pp. 629-633. New York, NY, USA: Oxford University Press. (https://doi.org/10.1093/acprof: oso/9780195100273.001.0001)

Remaud S, Gothie JD, Morvan-Dubois G \& Demeneix BA 2014 Thyroid hormone signaling and adult neurogenesis in mammals. Frontiers in Endocrinology 5 62. (https://doi.org/10.3389/fendo.2014.00062)

Remaud S, Ortiz FC, Perret-Jeanneret M, Aigrot MS, Gothie JD, Fekete C, Kvarta-Papp Z, Gereben B, Langui D, Lubetzki C, et al. 2017 Transient hypothyroidism favors oligodendrocyte generation providing functional remyelination in the adult mouse brain. eLife 6 e29996. (https://doi.org/10.7554/eLife.29996)

Rieben C, Segna D, da Costa BR, Collet TH, Chaker L, Aubert CE, Baumgartner C, Almeida OP, Hogervorst E, Trompet S, et al. 2016 Subclinical thyroid dysfunction and the risk of cognitive decline: a meta-analysis of prospective cohort studies. Journal of Clinical Endocrinology and Metabolism 101 4945-4954. (https://doi. org/10.1210/jc.2016-2129)

Roepke TK, King EC, Reyna-Neyra A, Paroder M, Purtell K, Koba W, Fine E, Lerner DJ, Carrasco N \& Abbott GW 2009 Kcne2 deletion uncovers its crucial role in thyroid hormone biosynthesis. Nature Medicine 15 1186-1194. (https://doi.org/10.1038/nm.2029)

Santello M, Toni N \& Volterra A 2019 Astrocyte function from information processing to cognition and cognitive impairment.
Nature Neuroscience 22 154-166. (https://doi.org/10.1038/s41593-0180325-8)

Shannon P, Markiel A, Ozier O, Baliga NS, Wang JT, Ramage D, Amin N, Schwikowski B \& Ideker T 2003 Cytoscape: a software environment for integrated models of biomolecular interaction networks. Genome Research 13 2498-2504. (https://doi.org/10.1101/gr.1239303)

Szlejf C, Suemoto CK, Santos IS, Lotufo PA, Haueisen Sander Diniz MF, Barreto SM \& Benseñor IM 2018 Thyrotropin level and cognitive performance: baseline results from the ELSA-Brasil study. Psychoneuroendocrinology 87 152-158. (https://doi.org/10.1016/j. psyneuen.2017.10.017)

Toni N, Buchs PA, Nikonenko I, Povilaitite P, Parisi L \& Muller D 2001 Remodeling of synaptic membranes after induction of long-term potentiation. Journal of Neuroscience 21 6245-6251. (https://doi. org/10.1523/JNEUROSCI.21-16-06245.2001)

Tsien JZ, Huerta PT \& Tonegawa S 1996 The essential role of hippocampal CA1 NMDA receptor-dependent synaptic plasticity in spatial memory. Cell 87 1327-1338. (https://doi.org/10.1016/s00928674(00)81827-9)

Vorhees CV \& Williams MT 2006 Morris water maze: procedures for assessing spatial and related forms of learning and memory. Nature Protocols 1 848-858. (https://doi.org/10.1038/nprot.2006.116)

Zaidman JL, Czerniak P \& Pinto N 1985 RIA examinations of CSF hormones as a method of demonstrating leakage through the bloodbrain and brain-CSF barriers. European Journal of Nuclear Medicine $\mathbf{1 1}$ 323. (https://doi.org/10.1007/bf00252346)

Zhang ZHX, LI H, Zhao H, Huang J, Wei J, Wang J, Li S, Yang E, Wu J, et al. 1999 The mini-mental state examination in the Chinese residents population aged 55 years and over in the urban and rural areas of Beijing. Chinese Journal of Neurology 32 1-7. (https://doi. org/10.3760/j.issn:1006-7876.1999.03.006)

Zhang W, Tian LM, Han Y, Ma HY, Wang LC, Guo J, Gao L \& Zhao JJ 2009 Presence of thyrotropin receptor in hepatocytes: not a case of illegitimate transcription. Journal of Cellular and Molecular Medicine $\mathbf{1 3}$ 4636-4642. (https://doi.org/10.1111/j.1582-4934.2008.00670.x)

Zuber B, Nikonenko I, Klauser P, Muller D \& Dubochet J 2005 The mammalian central nervous synaptic cleft contains a high density of periodically organized complexes. PNAS 102 19192-19197. (https:// doi.org/10.1073/pnas.0509527102)

Received in final form 3 April 2020

Accepted 21 April 2020

Accepted Manuscript published online 21 April 2020 (c) 2020 Society for Endocrinology Published by Bioscientifica Ltd. Printed in Great Britain 